\title{
Development of Active Breathing Micro PEM Fuel Cell
}

\author{
Young Ho Seo', Hyung Jin Kim', Woong Ki Jang', and Byeong Hee Kim," \\ 1 Department of Mechanical and Mechatronic Engineering, Kangwon National University, 1 Kangwon-daehak-gil, Chunchon, Gangwon, South Korea \\ \# Corresponding Author / E-mail address: kbh@kangwon.ac.kr, TEL: +82-33-250-6374, FAX: +82-33-259-5551
}

KEYWORDS: Air breathing, Planar PEM fuel cells (PEMFCs), Synthetic jet breather, Balance of plant (BOP)

\begin{abstract}
Air-breathing proton exchange membrane fuel cells (AB-PEMFCs) can reduce the cost, complexity, noise, volume, and weight of fuel cells and can enhance their reliability. However, such cells are still typically characterized by low output power densities. In this study, to overcome the inherent weaknesses of low power density and oxygen concentration without mobility loss, we have adopted a microscale synthetic jet air breather (a crucial balance-of-plant device), which supplies air to the cathode side of the flow field of a planar AB-PEMFC. A synthetic jet air breather consists of a PZT diaphragm actuator, small cylindrical cavity, inlet and outlet channels, and a pump body. The flow rate of the fabricated synthetic jet air breather is more than $400 \mathrm{cc} / \mathrm{min}$ at $550 \mathrm{~Hz}$ with a power consumption of less than $0.3 \mathrm{~W}$. An AB-PEMFC equipped with a microscale-synthetic jet air breather shows higher performance and stability, obtaining a maximum power density of $188 \mathrm{~mW} / \mathrm{cm}^{2}$ at $400 \mathrm{~mA} / \mathrm{cm}^{2}$.
\end{abstract}

Manuscript received: January 13, 2014 / Revised: March 13, 2014 / Accepted: March 20, 2014

\section{Introduction}

While state-of-the-art battery technology has improved considerably in recent years, the functionality, operating speed, and lifetime of many portable devices are still limited because of the low amount of energy that can be stored within them. ${ }^{1}$ However, miniaturized fuel cells which can directly convert chemical energy into electrical energy from a chemical reaction between oxygen and hydrogen have several advantages such as high energy conversion efficiency, low emission of pollutants, light weight and high power density comparing to conventional batteries. ${ }^{2}$ For the last two decades, fascinated by their high power density and relatively easy implementation in electronic telecommunication and computing applications, many researchers as well as electronics companies (e.g., Toshiba, Samsung, Hitachi, Sharp, LG, Sony, etc.) have been developing microscale pilot DMFCs (Direct Methanol Fuel Cells). ${ }^{3-5}$ However, because DMFCs still have critical limitations because of high cost resulting from a relatively high $\mathrm{Pt}$ loading, balance-of-plant complexity, and methanol crossover, their practical implementation is still difficult.

Therefore, PEMFCs have been in the spotlight as a promising candidate for a microscale mobile power source. A polymer electrolyte membrane fuel cell offers the advantages of a compact package and near room temperature operation. To reduce their manufacturing costs, complexity, noise, volume, and weight as well as to enhance their reliability, a passive air supplying scheme, i.e., an air-breathing cathode open to the atmosphere, is preferred over active cells that use massive conventional pumps or fans located at the cathode side. ${ }^{1,6-8}$ Although parasitic power losses from conventional pumps or fans can be reduced, these types of cooling devices are still typically characterized by low output power densities compared to active convection fuel cells. In addition, crucial issues still remain, such as the depletion of local oxygen concentration adjacent to the cathode in the absence of convection, which results in a sluggishness of oxygen diffusion over longer durations; ${ }^{9}$ hydrogen starvation or undersupply at the anode side caused by a mass or water back diffusion in the dead-end mode, resulting in non-uniform current density and high cathode potential; ${ }^{10}$ and the formation and aggregation of water droplets in the cathode flow channels. ${ }^{11}$

One of the key technologies that can overcome the inherent weaknesses of low power density and oxygen concentration on the cathode side in free-air-breathing PEMFC schemes, or so-called airbreathing PEMFCs (AB-PEMFCs), without losing mobility, is introducing a microscale air pump. Because a microscale pump can feed sufficient air into a fuel cell, the electrode size can be reduced, which can result in a downsizing of the entire fuel cell system and simultaneous enhancement in power density. In addition, introducing a microscale air pump can help remove generated water in the cathode as a by-product of the fuel cell reaction. Generally, in a free air-breathing device, generated water should clog the pores or channels of the GDL in the cathode and prevent air from being sufficiently fed to the 
cathode. Pumped air can push out and vaporize the clogged channels and ensure that a sufficient area is available for air contact. However, while a few studies on the use of a bimorph PZT diaphragm actuator 12 have been reported and despite piezoelectric actuation providing good reliability, energy efficiency, and moderated displacement, the flow rates and pressures achieved so far are insufficient to meet the amounts required for supplying sufficient air to the flow field on the cathode side, which has serpentine or parallel channels. Furthermore, previously developed microscale air pumps are not adequate for integrating with actual air-breathing cells because of their configuration-discordance.

This paper proposes a novel small-scale synthetic jet type air breather, which is a zero-mass-flux device that converts electrical energy into momentum, for helping air breathing of the cathode side of AB-PEMFCs without changing significantly the existing configuration of a fuel cell. Zero-net-mass-flux synthetic air jets are able to perform "push" and "pull" functions to vector a primary jet into a designated direction and have generally been applied to a wide number of applications. Since proposed by Coles, ${ }^{13}$ the utility of synthetic jet actuators has been analyzed and demonstrated in a variety of applications including plane or round turbulent jets, ${ }^{14}$ hybrid synthetic jets, ${ }^{15,16}$ microjet modulator arrays, ${ }^{17}$ free jets control $^{18}$ and thermal management. ${ }^{19}$ The developed and fabricated synthetic jet type air breather proposed herein was installed at the cathode side of planar airbreathing fuel cells. Our experiments showed that the developed synthetic jet type air breather could enhance the efficiency and performance of AB-PEMFCs.

\section{PEM Cell Design and Manufacturing}

The planar single-cell design including a synthetic jet air breather is illustrated in Fig. 1(a). The anode side is composed of a grade 316 stainless steel end plate, a copper current collector, a graphite flow field, and a gasket for sealing (not shown in Fig. 1(a)). Because 0.125" gas connectors are used for the hydrogen inlet and outlet, the thickness of the end plate is $10 \mathrm{~mm}$. However, this thickness can be reduced if smaller gas connectors are used or if the hydrogen tube is directly connected (or bonded) to the inlet of the flow channel. Although the cathode side is also composed of an end plate, a copper current collector, a flow field, and a gasket for sealing, in contrast to the anode side, all parts have air openings for breathing ambient air. Oxygen (actually air) used in the chemical reaction moves through the gas diffusion layer to the cathode electrode through a diffusion process. The thickness of the end plate is $4 \mathrm{~mm}$.

For the membrane electrode assembly (MEA) compartment, SIGRACET® GDL10-BB carbon paper (manufactured by SGL Technologies $\mathrm{GmbH}$ ) and PRIMEA ${ }^{\circledR}$ MEA Series 5510 with platinum loading of $0.3 \mathrm{mg} \mathrm{cm}^{-2}$ on both sides (manufactured by W.L. Gore \& Associates) were used for the gas diffusion backing layer and MEA on the anode side, respectively. For the cathode side, two kinds of $1.5-\mathrm{mm}$ thick gas diffusion backings were used, specifically, ®SIGRACET PGP 30 AA \#18802 and \#19802 carbon sheets (manufactured by SGL Technologies $\mathrm{GmbH}$ ). These gas diffusion media can offer sufficient mechanical rigidity, which results in the minimization of the support

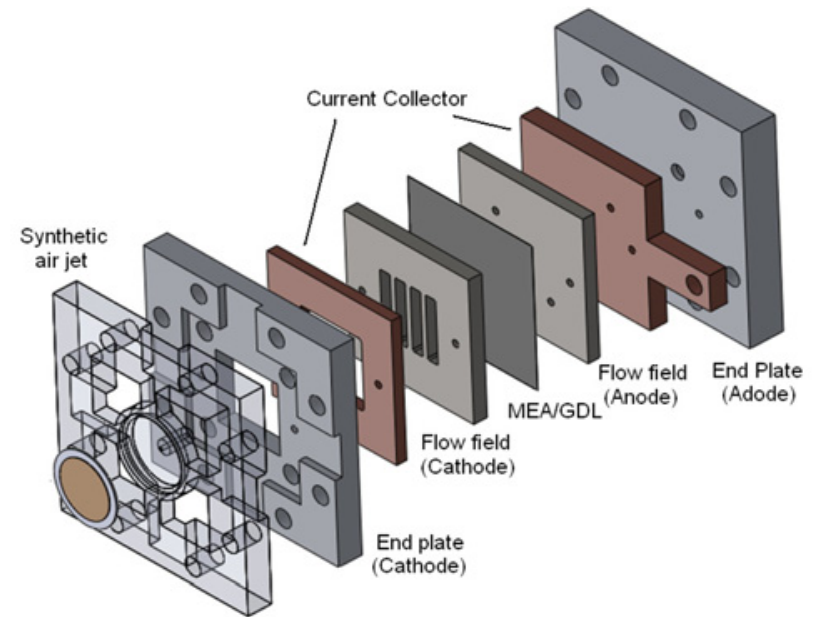

(a) Schematic of single cell (including synthetic jet type breather)

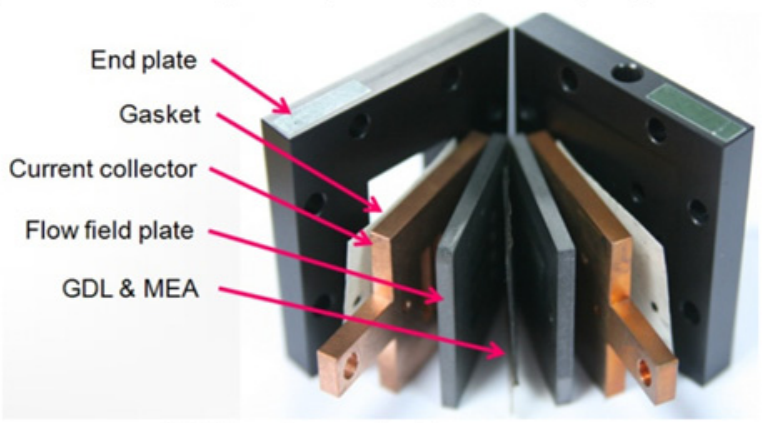

(b) Manufactured cell components

Fig. 1 Air-breathing planar PEM fuel cell

structure. The porosities of the carbon sheets calculated from the densities given by the manufacturer were $78 \%$ for $\# 18802$ and $58 \%$ for $\# 19802$. According to the manufacturer, the area-specific resistance of materials \#18802 and \#19802 were 110 and $90 \mathrm{~m} \Omega / \mathrm{cm}^{2}$, respectively. Fig. 1(b) shows a photograph of the fabricated and bolt-assembled ABPEMFC. For the air-breathing designs, the cathode flow field was machined with various opening ratios (40 to $72 \%$ ) with slit and window openings. The active area of the cell was $4 \mathrm{~cm}^{2}$.

\section{Synthetic Jet Air Breather Design and Fabrication}

Synthetic jet pumping has attracted considerable attention because of its potential application in areas such as active flow control, micropumping, and thermal management in several microelectronic devices. A synthetic jet is a zero-net-mass-flux jet fluid flow, in which a stream of one fluid is mixed with the surrounding medium through the use of a dedicated actuator. These synthetic jet actuators can be developed in a number of ways, such as by using an electromagnetic driver, piezoelectric driver, or even a mechanical driver such as a piston.

In this paper, a microscale synthetic jet actuator is newly developed and used as a blower for assisting air breathing the cathode side flow field of PEMFCs. Fig. 2(a) shows the front, rear, and isometric schematic views of the designed synthetic jet air breather. When the PZT membrane of a synthetic jet moves hundreds of times per second, the breathing and supplying mode are repeated. This fast pulling and pushing of air through a small jet nozzle induces a vortex ring that 


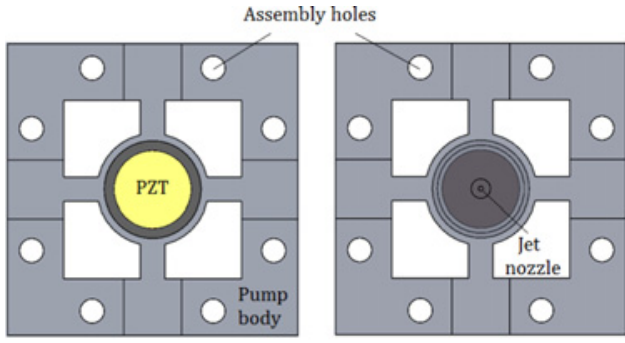

(a) Front, rear, and isometric views

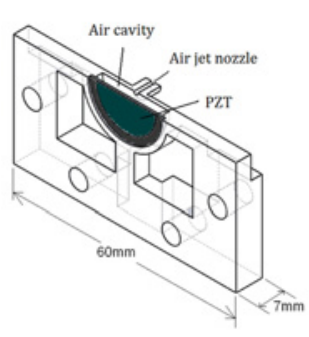

(b) Manufactured and equipped on fuel cell

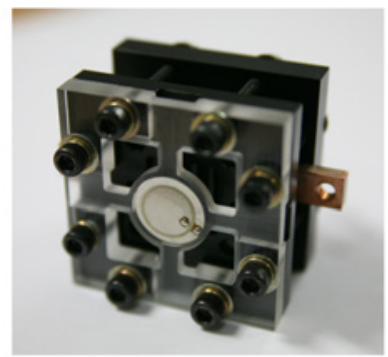

Fig. 2 Synthetic jet air breather design and fabrication

separates the flow field in front of the nozzle and produce air jet. ${ }^{20}$ The body the synthetic jet air breather is made up of transparent PMMA and is $60 \times 60 \times 7 \mathrm{~mm}$ in size. It has four openings and air vents for air circulation as well as eight through holes for the cell assembly. The air cavity is $18-\mathrm{mm}$ wide and 3-mm deep, creating a volume of $0.76 \mathrm{cc}$. A PZT diaphragm mounted on the front center of the breather body has a $20-\mathrm{mm}$ diameter and $0.5-\mathrm{mm}$ thickness and is made of stainless steel for high stiffness. The piezoelectric material, lead zirconate titanate $\left(\mathrm{Pb}\left[\mathrm{Zr}_{\mathrm{x}} \mathrm{Ti}_{1-\mathrm{x}}\right] \mathrm{O}_{3}\right)$, is coated on one side of the stainless steel diaphragm at a thickness of $0.2 \mathrm{~mm}$. The maximum displacement of the PZT, which is measured using a laser interferometer, is about $\pm 20 \mu \mathrm{m}$ at $200 \mathrm{~V}$ and $100 \mathrm{~Hz}$. Fig. 2(b) shows the manufactured synthetic jet air breather mounted onto an air-breathing planar PEM fuel cell.

\section{Experimental Setup}

Fig. 3 shows a setup used for the flow rate measurement test. To eliminate the effects of environmental airflow, the test system was placed in a polymer chamber. A flow sensor (Schiltknecht Messtechnik, ThermoAir3) with a measuring range of 0.01 to $5 \mathrm{~m} / \mathrm{s}$ was placed in front of the pump outlet, and a Labview-based DAQ system installed on a personal computer was used for data processing. In general, diaphragm-type PZT actuators may create noise during their operation. In this study, in order to minimize such vibration noise, several sound level tests were performed with respect to the diameter, voltage level and wave shape changes using a sound measuring system based on the Symphonie System (Model: 01dB, manufactured by MVI Technologies Group), which is depicted in Fig. 4.

And to verify the validity and performance of the novel synthetic jet air breather on an air-breathing fuel cell, a performance test system was also built, as shown in Fig. 5. Regulated dry hydrogen (99.999\% purity) stored in a tank is supplied to the anode inlet through a mass flow controller (MFC, KOFLOC 8300, manufactured by KOFLOC, Co.). Because either hydrogen or oxygen or both are often supplied at rates greater than the stoichiometry rate, particularly when supplying air to the cathode side instead of oxygen, ${ }^{21}$ the stoichiometry rate is set to 1.5 (air-fuel ratio) by maintaining a hydrogen flow rate of $30 \mathrm{cc} / \mathrm{min}$. The flow field of the anode side has a single serpentine channel (not clearly illustrated in Fig. 1(a)) and an open end. The atmosphere at the cathode side is $27^{\circ} \mathrm{C}$ with $45 \%$ relative humidity.

Before evaluating the performance of a fuel cell, In order to verify the internal resistance and charge-transfer resistance in the air-breathing fuel cell systems, impedance analysis was performed using

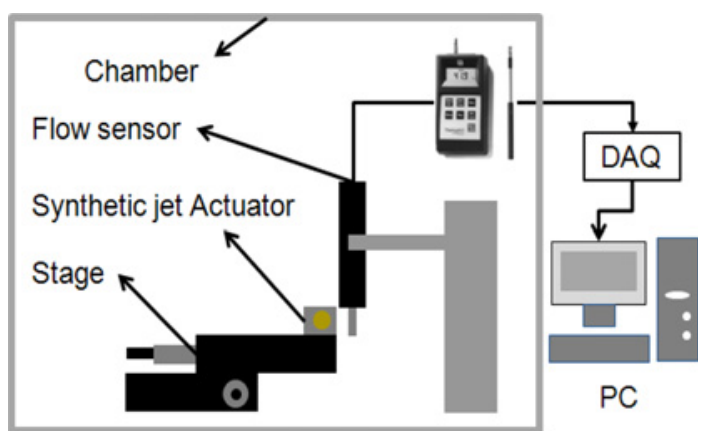

Fig. 3 Flow rate measurement setup

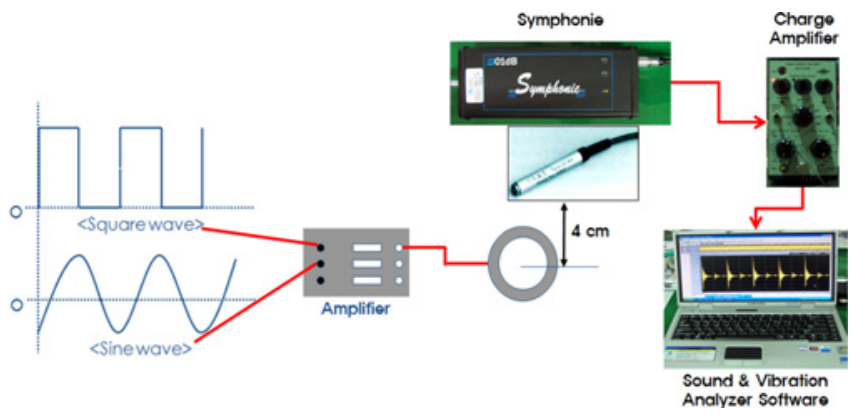

Fig. 4 Sound level test setup

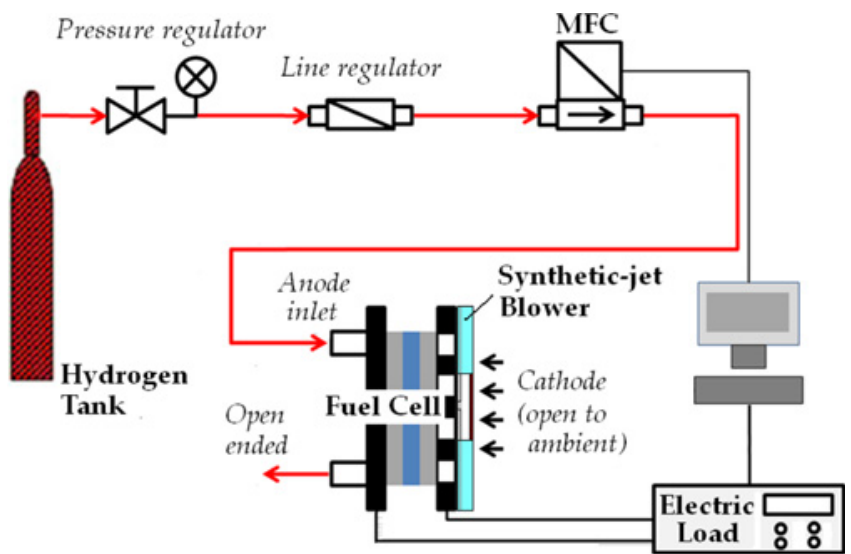

Fig. 5 Performance test setup

electrochemical impedance spectroscopy (EIS, KFM2030, Kikusui Electronics Co). For the air-breathing fuel cell, internal resistance was reduced from $468.5 \mathrm{~m} \Omega \mathrm{cm}^{2}$ to $168.48 \mathrm{~m} \Omega \mathrm{cm}^{2}$, and the chargetransfer resistance was also reduced from $3831.88 \mathrm{~m} \Omega \mathrm{cm}^{2}$ to $2151.1 \mathrm{~m} \Omega-\mathrm{cm}^{2}$, when the load current was increased from $100 \mathrm{~mA}$ to $900 \mathrm{~mA}$. Because the hydration of electrolyte membrane was 
insufficient at low load current, internal resistance and charge-transfer resistance were higher than those at high load current.

Generally speaking, there are two ways to plot polarization curves for evaluating the performance of a fuel cell: constant voltage (CV) mode and constant current (CC) mode. In this paper, the polarization curves are obtained in the $\mathrm{CV}$ mode by gradually increasing the current. The testing conditions, including the hydrogen flow rate, temperature, relative humidity, and electrical data, were measured and processed using a monitoring program (Agilent VEE, Agilent Technologies, Co.) installed on a personal computer. To assure the stability and consistency of the tests, 40 -cycle preliminary activations were performed before primary performance testing was carried out.

Air-breathing fuel cell was operated under room temperature of $21.5^{\circ} \mathrm{C}$. In the preliminary test, temperature of the current collector in the fuel cell was measured by infrared camera (NCE-TH5100). Temperature of fuel cell was increased from $21.5^{\circ} \mathrm{C}$ to $57^{\circ} \mathrm{C}$, when the fuel cell generated the current density of $250 \mathrm{~mA} / \mathrm{cm}^{2}$ during $180 \mathrm{~min}$. In the aspect of the cooling of the fuel cell, active-air-breathing fuel cell is more suitable to mobile application rather than free-air-breathing one.

\section{Results and Discussion}

The measured results for an increase in frequency and air hole diameter $d$ are shown in Fig. 6. The flow rate increases as air hole diameter $d$ increases. However, as the frequency of the diaphragm increases, the flow rate of the synthetic jet blower rises to its maximum value at particular frequencies and gradually falls to zero when the frequency increases further. The maximum flow rates reach about 500 , 830 , and $1300 \mathrm{cc} / \mathrm{min}$ when the air hole diameters are 1,2 , and $3 \mathrm{~mm}$, respectively. When simply considering the flow rate, we might think that a larger hole is preferable to smaller holes in the design of a synthetic jet blower; however, in practical situations, the particular frequency that produces the maximum flow rate rises from 670 to $970 \mathrm{~Hz}$ when the air hole increases from 1 to $3 \mathrm{~mm}$ for a $400-\mathrm{V}$ sine wave. This means that the particular frequency approaches around $1000 \mathrm{~Hz}$ when the diameter of the air hole increases to $3 \mathrm{~mm}$.

The noise level test results in Fig. 7 shows that the sine wave input voltage is much superior to the square wave input voltage in terms of noise reduction. Also relatively higher frequency and voltage levels definitely produce greater amounts of noise. Because a higher frequency creates more noise, a smaller hole is preferable to a larger hole as long as the synthetic jet air breather can maintain the desired air supply to the cathode side flow field. Therefore, a 1-mm air jet nozzle diameter is selected. The maximum back pressure obtained is $5 \mathrm{kPa}$ when the frequency is $670 \mathrm{~Hz}$, and the supply voltage is a $400-\mathrm{V}$ sine wave.

Fig. 8 compares the polarization curve of a cell equipped with a synthetic jet air breather on the cathode side with those of convectiontype and fan-blowing-type cells when the opening ratio of the cathode is $61 \%$. The cells equipped with a synthetic jet air breather or a fan (manufactured for CPU cooling) showed a maximum power density that was about $40 \%$ higher than that of the plain air-breathing fuel cell. This is because such cells can provide sufficient air supply to the cathodes and remove generated water through fast vaporization, which minimizes concentration loss.

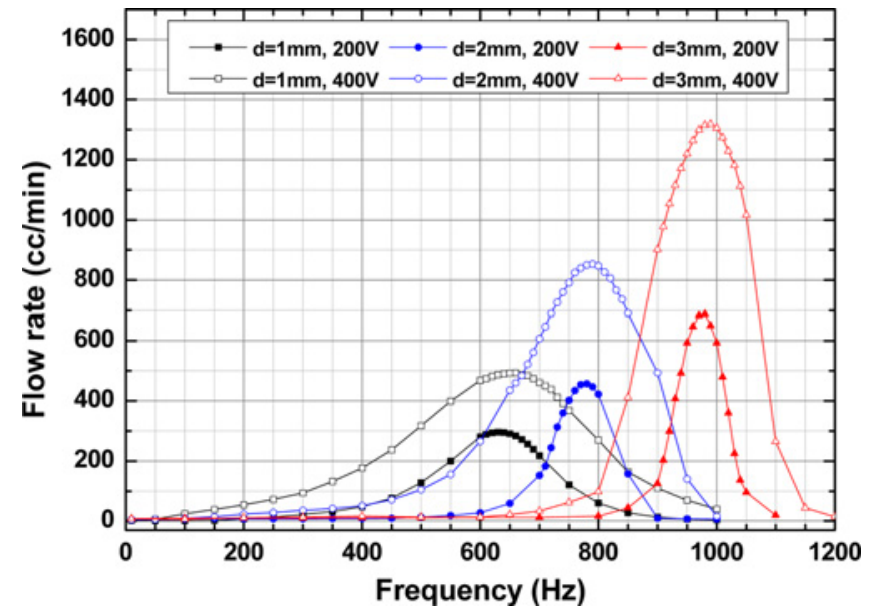

Fig. 6 Flow rate dependence on frequency and air hole diameter $d$

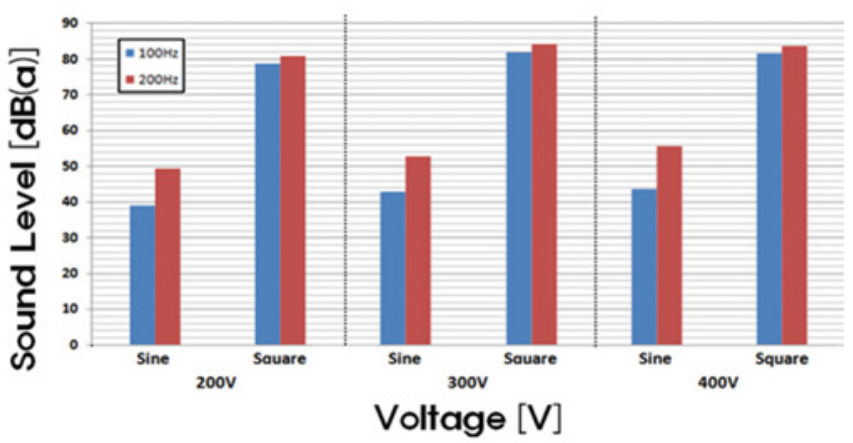

Fig. 7 Sound level test results

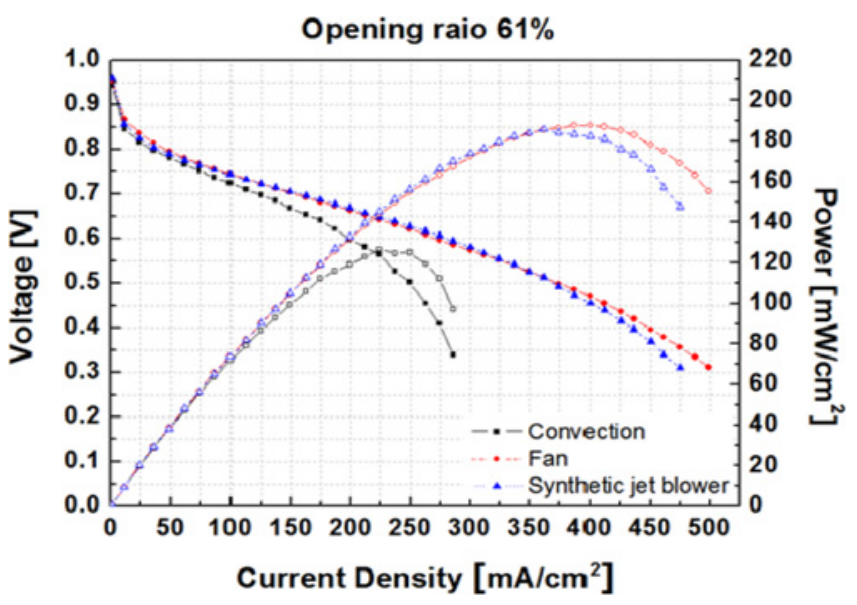

Fig. 8 Comparison of polarization curves and power levels

Such phenomena can be easily observed by performing various continuous operation tests, as shown in Fig. 9. While the output voltage of a convection-type fuel cell is gradually reduced by more than $27 \%$ within $1 \mathrm{~h}$ because of the depletion of local oxygen concentration adjacent to the cathode, the output voltages generated from a cell equipped with a breather decrease by less than $7 \%$. In light of this phenomenon, it can be inferred that the synthetic jet air breather shows outstanding effectiveness in managing water on the cathode side. The maximum power density is $188 \mathrm{~mW} / \mathrm{cm}^{2}$ at $400 \mathrm{~mA} / \mathrm{cm}^{2}$. With regard to only the power density, the fan shows a slightly better result than the synthetic jet air breather. However, one of the important factors that determine the usefulness of auxiliary devices is power 


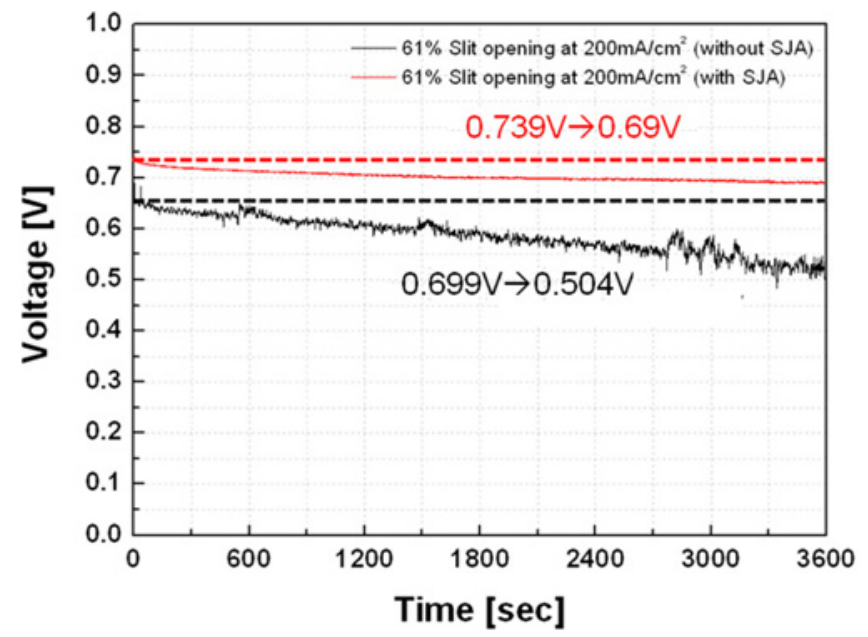

Fig. 9 Degradation of voltage output dependence on time ( $\mathrm{SJA}=$ Synthetic Jet Air breather)

consumption. synthetic jet air breather consumes only $0.3 \mathrm{~W}$ (at $3 \mathrm{~V}, 80 \mathrm{~mA}$, $550 \mathrm{~Hz}$ ) or less when a SP4423 EL lamp driver is used as the controller for PZT actuation. However, a fan generally consumes more than $1 \mathrm{~W}$ at $12 \mathrm{~V}$, 0.1 A. Consequently, from the viewpoint of overall system efficiency, it can be said that the synthetic jet air breather is more useful than a fan with regard to mass transfer control on the cathode side.

\section{Conclusions}

A synthetic jet air breathing type PEMFC was designed and fabricated to enhance the performance of conventional air-breathing PEMFCs. Maximum flow rates are achieved when the air hole diameter is $3 \mathrm{~mm}$. In this case, however, the frequency necessary for producing the maximum flow rate is $970 \mathrm{~Hz}$, which induces relatively harsh noises. Therefore, a smaller hole with a lower frequency $(1 \mathrm{~mm}$ and $670 \mathrm{~Hz})$ is preferred. The maximum back pressure obtained is $5 \mathrm{kPa}$ when the frequency is $670 \mathrm{~Hz}$ and supply voltage is a $400-\mathrm{V}$ sine wave. When the opening ratio of the cathode is $61 \%$, cells equipped with a synthetic jet air breather show a maximum power density that is about $40 \%$ higher than that of a conventional air-breathing fuel cell. Because they can provide sufficient air supply to the cathodes and remove generated water through fast vaporization, the use of cells with a synthetic jet air breather can dramatically minimize concentration loss. The optimally developed synthetic jet air breather shows almost the same air blowing functionality as microfans, although it consumes $40 \%$ less power compared to conventional fan-type blowers. Consequently, in terms of overall system efficiency, the synthetic jet air breather is more useful than fan-type blowers with regard to mass transfer control on the cathode side.

\section{ACKNOWLEDGEMENT}

This work was supported by the Human Resources Development program (No. 20134030200240) of the Korea Institute of Energy Technology Evaluation and Planning (KETEP) grant funded by the Korea government Ministry of Trade, Industry and Energy.

\section{REFERENCES}

1. Meyers, J. P. and Maynard, H. L., "Design Considerations for Miniaturized Pem Fuel Cells," Journal of Power Sources, Vol. 109, No. 1, pp. 76-88, 2002.

2. Li, P. W., Zhang, T., Wang, Q. M., Schaefer, L., and Chyu, M. K., "The Performance of Pem Fuel Cells Fed with Oxygen through the Free-Convection Mode," Journal of Power Sources, Vol. 114, No. 1, pp. 63-69, 2003.

3. Yen, T., Fang, N., Zhang, X., Lu, G., and Wang, C., "A Micro Methanol Fuel Cell Operating at Near Room Temperature," Applied physics letters, Vol. 83, No. 19, pp. 4056-4058, 2003.

4. Mench, M., Wang, Z., Bhatia, K., and Wang, C., "Design of a Micro Direct Methanol Fuel Cell ( $\mu \mathrm{dmfc})$," Proc. of the IMECE, 2001.

5. Lu, G., Wang, C., Yen, T., and Zhang, X., "Development and Characterization of a Silicon-Based Micro Direct Methanol Fuel Cell,” Electrochimica Acta, Vol. 49, No. 5, pp. 821-828, 2004.

6. Schmitz, A., Wagner, S., Hahn, R., Uzun, H., and Hebling, C., "Stability of Planar Pemfc in Printed Circuit Board Technology," Journal of Power Sources, Vol. 127, No. 1, pp. 197-205, 2004.

7. Hottinen, T., Mikkola, M., and Lund, P., "Evaluation of Planar FreeBreathing Polymer Electrolyte Membrane Fuel Cell Design," Journal of Power Sources, Vol. 129, No. 1, pp. 68-72, 2004.

8. Kim, S. H., Cha, H. Y., Miesse, C. M., Jang, J. H., Oh, Y. S., and Cha, S. W., "Air-Breathing Miniature Planar Stack using the Flexible Printed Circuit Board as a Current Collector," International Journal of Hydrogen Energy, Vol. 34, No. 1, pp. 459-466, 2009.

9. Jung, G. B., Lo, K. F., Su, A., Weng, F. B., Tu, C. H., and et al., "Experimental Evaluation of an Ambient Forced-Feed Air-Supply Pem Fuel Cell," International Journal of Hydrogen Energy, Vol. 33, No. 12, pp. 2980-2985, 2008.

10. Baumgartner, W., Parz, P., Fraser, S., Wallnöfer, E., and Hacker, V., "Polarization Study of a PEMFC with Four Reference Electrodes at Hydrogen Starvation Conditions," Journal of Power Sources, Vol. 182, No. 2, pp. 413-421, 2008.

11. Ous, T. and Arcoumanis, C., "The Formation of Water Droplets in an Air-Breathing PEMFC," International Journal of Hydrogen Energy, Vol. 34, No. 8, pp. 3476-3487, 2009.

12. Yang, X., Zhou, Z., Cho, H., and Luo, X., "Study on a Pzt-Actuated Diaphragm Pump for Air Supply for Micro Fuel Cells," Sensors and Actuators A: Physical, Vol. 130, pp. 531-536, 2006.

13. Savas, Ö. and Coles, D., "Coherence Measurements in Synthetic Turbulent Boundary Layers," Journal of Fluid Mechanics, Vol. 160, pp. 421-446, 1985.

14. Smith, B. L. and Glezer, A., "The Formation and Evolution of Synthetic Jets," Physics of Fluids (1994-present), Vol. 10, No. 9, pp. 2281-2297, 1998.

15. Tesař, V., "Configurations of Fluidic Actuators for Generating 
Hybrid-Synthetic Jets," Sensors and Actuators A: Physical, Vol. 138, No. 2, pp. 394-403, 2007.

16. Tesař, V., Trávníček, Z., Kordík, J., and Randa, Z., "Experimental Investigation of a Fluidic Actuator Generating Hybrid-Synthetic Jets," Sensors and Actuators A: Physical, Vol. 138, No. 1, pp. 213220, 2007.

17. Coe, D. J., Allen, M. G., Rinehart, C. S., and Glezer, A., "Pneumatically Actuated Micromachined Synthetic Jet Modulators," Sensors and Actuators A: Physical, Vol. 132, No. 2, pp. 689-700, 2006.

18. Tamburello, D. A. and Amitay, M., "Active Control of a Free Jet using a Synthetic Jet," International Journal of Heat and Fluid Flow, Vol. 29, No. 4, pp. 967-984, 2008.

19. Tan, X. M. and Zhang, J. Z., "Flow and Heat Transfer Characteristics under Synthetic Jets Impingement Driven by Piezoelectric Actuator," Experimental Thermal and Fluid Science, Vol. 48, pp. 134-146, 2013.

20. Choi, J. P., Kim, K. S., Seo, Y. H., and Kim, B. H., "Design and Fabrication of Synthetic Air-Jet Micropump," Int. J. Precis. Eng. Manuf., Vol. 12, No. 2, pp. 355-360, 2011.

21. Lamminie, J. and Dicks, A., "Fuel Cell Explained," $2^{\text {nd }}$ ed., John Wiley \& Sons, pp. 395-396, 2003.

22. Hottinen, T., Mikkola, M., and Lund, P., "Evaluation of Planar FreeBreathing Polymer Electrolyte Membrane Fuel Cell Design," Journal of Power Sources, Vol. 129, No. 1, pp. 68-72, 2004. 